\title{
1 First identification of non-human stencil hands at Wadi Sūra II (Egypt): a morphometric study for new insights into rock art symbolism
}

Authors Emmanuelle Honoré ${ }^{1}$, Thameur Rakza ${ }^{2}$, Brigitte Senut ${ }^{3}$, Philippe Deruelle ${ }^{2}$,

4 Emmanuelle Pouydebat ${ }^{4}$

Affiliations ${ }^{1}$ McDonald Institute for Archaeological Research, Cambridge, Downing Street

Abstract In the Libyan Desert, Wadi Sūra II shelter hosts numerous stencil paintings believed to date to the Early and Mid-Holocene. Tiny hands have previously been considered to belong to human babies. We challenge this identification, having conducted a morphometric study to compare the archaeological material with samples of hands of babies born at term and preterm at the neonatal unit of the CHRU Jeanne de Flandre (Lille, France). The results show that the rock art small hands differ significantly in size, proportions and morphology from human hands. Potential biases between the different samples were quantified, but their average range cannot explain the observed differences. Evidence suggest that the hand stencils belong to an animal, most probably a reptile. The identification of non-human pentadactyl hand stencils is unique in the field of rock art and raises new perspectives for understanding the rock art at Wadi Süra, and the behaviour and symbolic universe of the populations who made it.

Keywords Morphometry; Hand stencils; Rock art; Prehistory; Sahara.

In the Egyptian part of the Libyan Desert, erosion processes have shaped the great plateau of the Gilf el-Kebir (tabular surface of ca. 15000 sq. ft - 7500 sq. km), mostly composed of Tertiary Nubian sandstones ${ }^{1}$. This massif is surrounded by flat sand sheets to the East, the South and the West, and by the Great Sand Sea to the North. The plateau is deeply incised by numerous wadis, the flanks of which host natural shelters. In some of them, prehistoric rock art, paintings, stencils and engravings, can be seen on the walls, dating mainly from the Early and Mid-Holocene periods, called the "optimum", corresponding to the latest favorable interval ${ }^{2}$.

The shelter of Wadi Sūra I (improperly called "cave of swimmers") was discovered in 1933 by Laszlo de Almasy ${ }^{3}$. In the same area, a second - better preserved - great shelter was found in 2002 by J. \& M. Foggini ${ }^{4}$. Also called WG 21 according to the classification of A. Zboray ${ }^{5}$, the shelter of Wadi Sūra II is situated at the top of a dune overlooking a playa with alternating sediments from a former palaeolake formation. The shelter is a 20 meters large space, $8 \mathrm{~m}$ 
deep, defined by the rocky overhang and totally open to the outside, making the denomination "shelter" much more correct than the commonly used "cave" "6, 7 . On the wall, a central panel, up to 4 meters high above the floor, is covered mainly by paintings on a surface of nearly 100 sq. m. With more than 8000 figures and a very high number of superimpositions, Wadi Sūra II can be considered as the greatest - or one of the greatest - rock art site of the whole Sahara.

Among its oldest paintings, the Wadi Sūra II shelter contains a very high number of stencil paintings including hands, arms, feet, disks and sticks ${ }^{8}$. The number of hand stencils has been previously estimated at around 120 or $400^{9,10}$, but according to our own count there are about 900. Thirteen of these hand stencils are quite tiny. Eleven are located in the left part, and two more are scattered on the first third of the right side of the wall, close to the main oblique crack (Fig. 1)

Figure 1: Drawing and location of the small hand stencils in the Wadi Sūra II shelter. In grey, the areas with rock art. Hand stencils 4 and 7 could not be completely reconstructed.
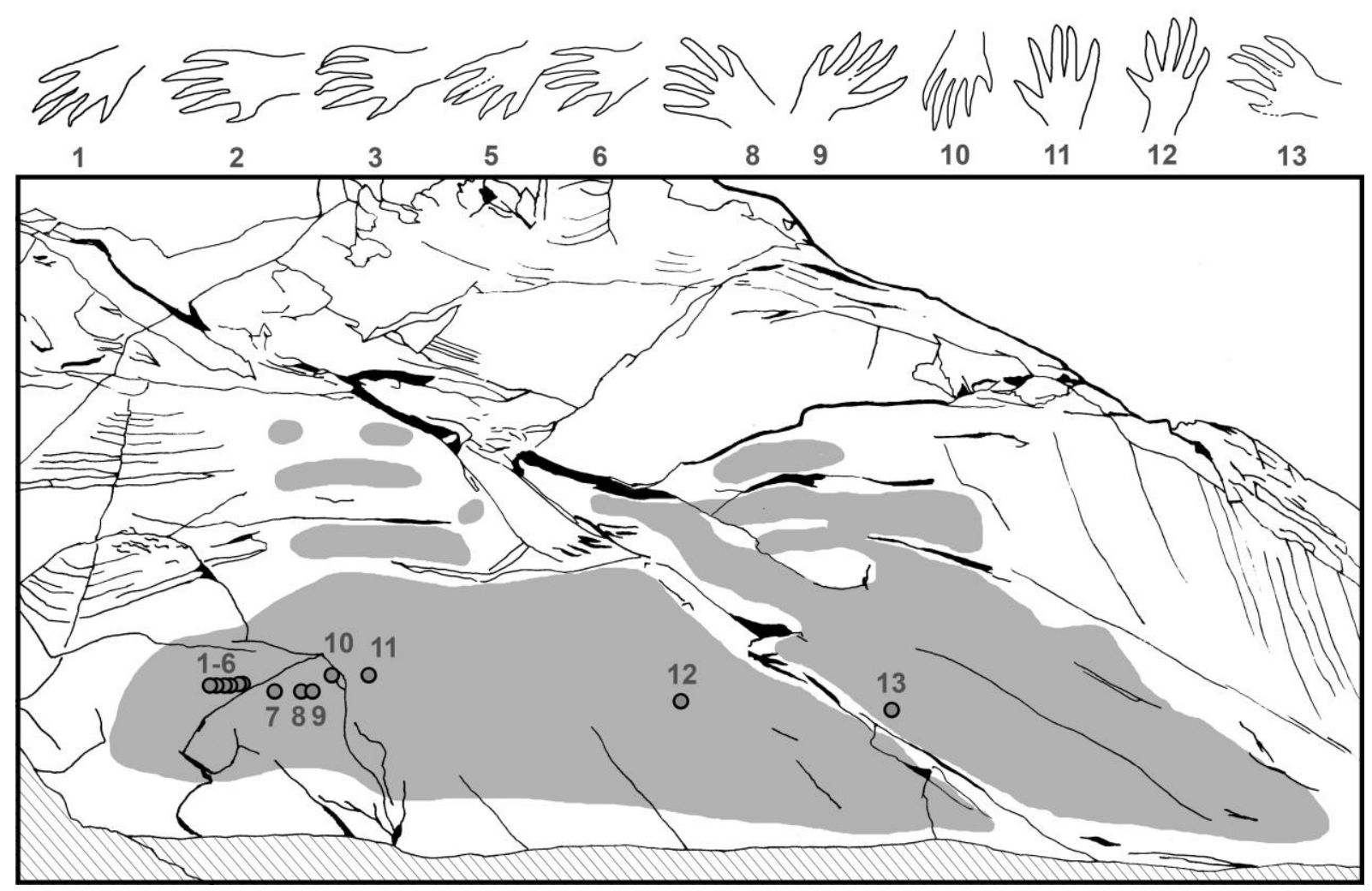

They have been identified by Le Quellec and others ${ }^{11}$ as being the hands of human babies or very young children. However, the atypical profile, the very small dimensions and the unexpectedly elongated proportions of these small hands led us to undertake a more precise identification of the stencils (Fig. 2). The average length of the small hands is $45.3 \mathrm{~mm}$ from the base of the palm to the end of the medius digit. The fingers are longer than the palm and they get progressively thinner distally, ending pointed. The aim of this study was to determine if the small hand stencils on Wadi Sūra II walls are human. For this purpose, we have compared the morphology of these small hands with human hand reference samples. 
Figure 2: Small hand stencils previously identified as human babies stencils. The particular layout of tiny hands in the pair of human hands seem to indicate a close relationship.
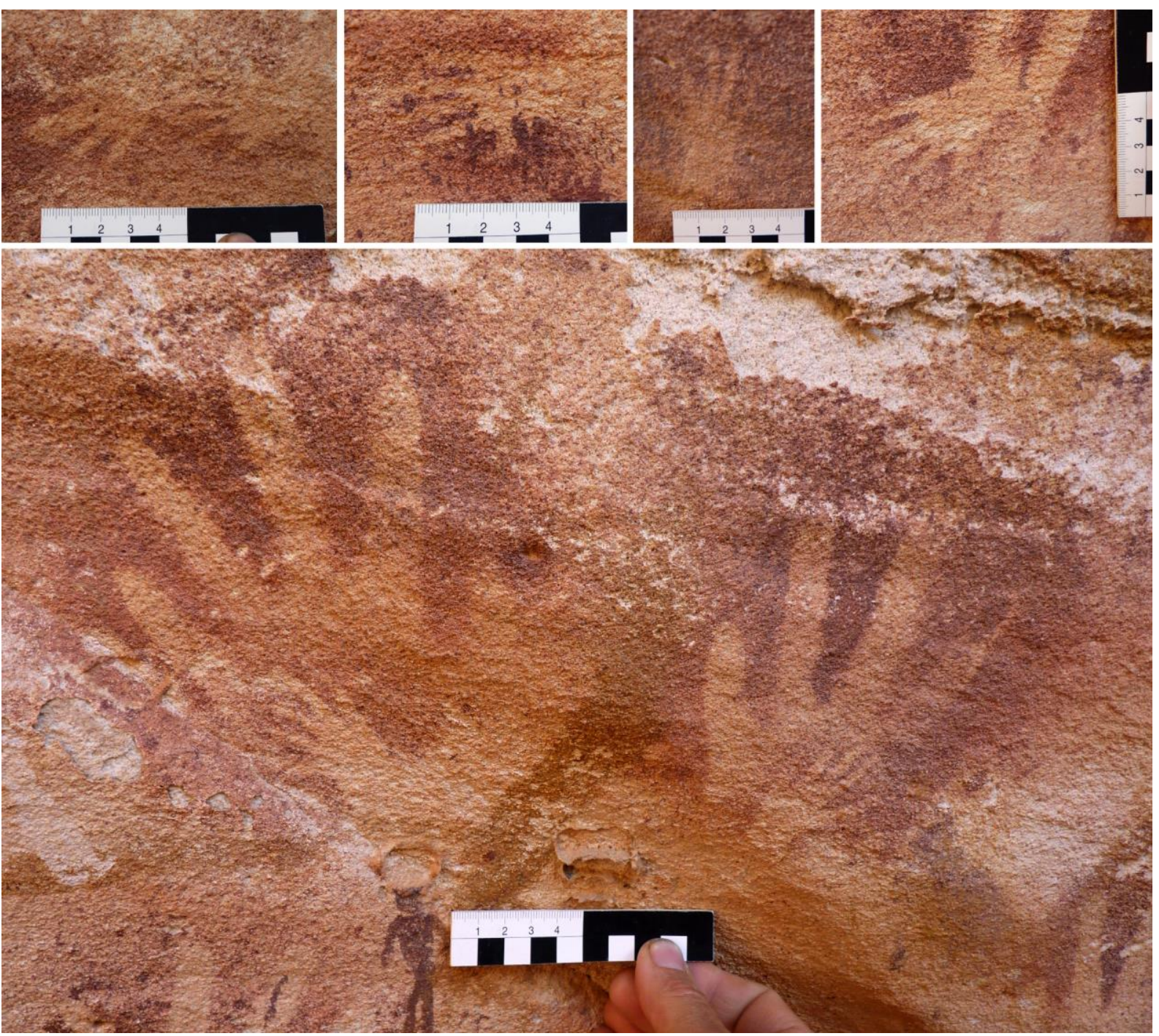

Hand stencils are a very common pattern in the rock art record. They were likely made by placing a hand or animal foot on the surface rock, and then blowing a pigment onto the substrate, to create an outline or a negative image of the hand or foot. As most hand stencils were made from human hands, morphometric studies on the archaeological record has concentrated so far on determining the relation of morphometric criteria of shape and size with group characteristics among humans ${ }^{12}$ : biological $\operatorname{sex}^{13}$ and age. Experiments have shown that some methods for determining sex according to morphometric criteria can be successful at a rate exceeding $85 \%{ }^{14}$. Our study focuses on an interspecific issue. We describe hand morphology in anthropometric terms, using both measurements and proportions (termed as ratios). Due to the differing nature of the samples, potential biases can occur and we tried to quantify their impact.

\section{The samples}

Five samples have been established (Tab. A1). Sample A is the archaeological sample of small rock art hands in Wadi Sūra II that we want to identify. Two individuals have not been taken into account as they were incomplete (Fig. 1). Sample B is constituted of 36 hands of 
living babies born at term, measured at birth, from 37 to 41 weeks gestational age. Sample $C$ is made of 25 hands of living pre-term babies, measured at birth, from 26 to 36 weeks gestational age (see Tab. $1 \& 2$ in Ref [15]). Sample D is the archaeological sample of 30 rock art large stencil hands from Wadi Sūra II, presumed to be blown from human adult hands. Sample $E$ is made of 30 hands of a current adult human population, measured on living individuals.

For the archaeological samples $(A$ and $D)$, measures were taken directly on the wall. The morphometric data gained from the human new-borns $(B$ and $C$ ) were collected in the Neonatalogy Unit of the CHRU Jeanne de Flandre (Lille University Hospital, France) between January and May 2014. Morphometric data on current adult hands $(E)$ were collected according to the same protocol at the same hospital in June 2014.

\section{Methods: the observational study \& the measurements}

The hypothesis to test was that these small hands would belong to young humans or human babies. We compared Sample A with Samples $B$ and $C$ in order to determine to what extent they are similar and, thus, the probability that the small stencils of Wadi Süra II could have been made by blowing paint on the hands of human babies. We then compared Sample D with Sample E, to determine and quantify the potential variations between measures taken directly on hands of a current European population, and measures taken on hand stencils of a North African population from the Holocene.

The sex of the individuals was not considered in the comparison, since the estimation of sex from hand stencils based on the Manning index ${ }^{16}$ and related methods involving measurements are applicable to human hands only. Measurements were also taken regardless of the side (right or left hand) since this factor is not statistically significant enough to impact or change the results at the scale of the study. Actually, according to a morphometric study led by E. Nowak on a child population, morphometric differences between right and left hands are less important than differences of hand measurements between males and females ${ }^{17}$.

We have selected the measurements criteria in accordance with the data available in the archaeological sample. Some of them are similar to measurements previously used by Snow ${ }^{13}$, Chazine and Noury ${ }^{18}$, and Sinclair et al. ${ }^{14}$ in the framework of other methods and purposes. In this study, 7 measurements were taken with a sliding caliper on each individual (Tab. A2, fig. 3):

- $\mathrm{W}_{\mathrm{i}}=$ width of the second digit (index) measured at the mid phalanx, just above the proximal inter-phalangeal joint.

- $\quad \mathrm{W}_{\mathrm{t}}=$ width of the first digit (thumb) measured at the middle of the proximal phalanx.

- $\quad R_{t}=$ Ray of the first digit (thumb) measured from the proximal end of the hand palm to the distal end of the thumb

- $\quad \mathrm{L}_{\mathrm{m}}=$ length of the middle digit, measured from the base of the digit

- $\quad L_{p}=$ length of the palm of the hand, measured from the proximal end of the hand to the distal end of the middle finger

- $\quad \mathrm{L}_{\mathrm{h}}=$ maximal length of the hand, measured from the proximal end of the hand to the distal end of the middle digit

- $\quad \mathrm{W}_{\mathrm{h}}=$ width of the hand, measured on the palm, just below the joint between the metacarpals and the proximal phalanges.

This formula can be checked: $\mathrm{L}_{h}=\mathrm{L} m+\mathrm{L}_{\mathrm{p}}$. And following this formula, the ratio $\mathrm{L}_{\mathrm{p}} / \mathrm{L}_{\mathrm{h}}$ has to be inversely proportional to the ratio $\mathrm{L} \mathrm{m} / \mathrm{L}$. 


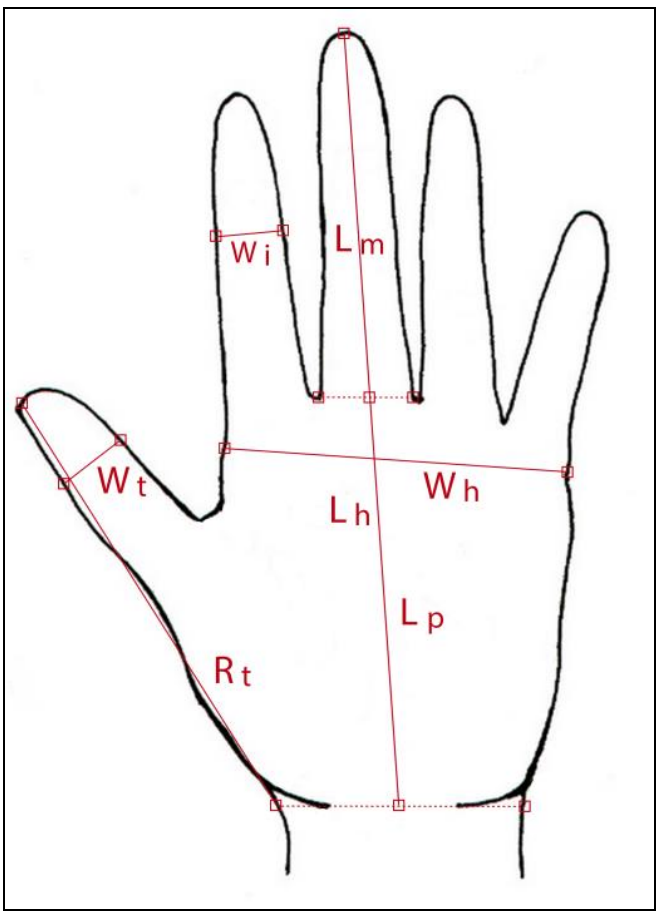

\section{The comparative study}

\subsection{Comparison with the hands of newborns}

Using a combination of two statistical tests, we tried to determine whether Samples $A$ and $B$ belong to a unique cluster or to two distinct populations. At first, with a Fisher-Snedecor test we have assessed the homoscedasticity of Sample A and Sample B for the seven variables (Tab. A3). Variances can be considered as almost identical since p-values vary from 0.05 (for $\mathrm{W}_{\mathrm{h}}$ ) to 0.58 (for $\mathrm{W}_{\mathrm{i}}$ ). $\mathrm{W}_{\mathrm{h}}$ and $\mathrm{L}_{\mathrm{h}}$ have the lowest $\mathrm{p}$-values and the variances are higher for the newborn sample than for the archaeological one. Then, in order to compare the average measurements for each parameter between the two samples, a T-test was performed since the samples are independent, small and of different sizes. The results show that, according to the parameters, Sample A and Sample B have between less than $0.39 \%$ (parameter $\mathrm{W}_{\mathrm{i}}$ ) and less than $0.01 \%$ (parameters $\mathrm{W}_{\mathrm{h}}, \mathrm{Lh}, \mathrm{Lp}$ and $\mathrm{Lt}$ ) chance to get the same averages. On eight criteria, four score less than $0.01 \%$ probability. This means that Samples $A$ and $B$ have an extremely low probability to represent the same population.

It can be observed that the newborn hands are all much longer (average length $=62.01 \mathrm{~mm}$ ) than the small negative hands (average length $=45.33 \mathrm{~mm}$ ) (Tab. A6). This raises the hypothesis that the small negative hands could be from smaller individuals, maybe from fetuses or pre-term newborns.

\subsection{Comparison with pre-term newborns hands}

We compared the Samples $A$ and $C$ with the same method (Tab. A4). The p-value is below the critical threshold of 0.05 for the parameters $\mathrm{L}_{\mathrm{t}}(=0.024)$ and $\mathrm{W}_{\mathrm{h}}(=0.02)$. Some parameters, especially the width of the index and the length of the medius, do not exclude that the two samples could be from the same population. But again four criteria on eight score less than $0.01 \%$ probability, which has led us to conclude that Sample A and $C$ have an extremely low probability to represent the same population. Concerning proportions, Sample B and Sample C 
159 seem to be very close, whereas Sample A significantly differs on 6 kinds of average ratios 160 (Tab. A7, fig. 4). This means that hand proportions do not greatly vary between the pre-term 161 babies and the newborns at term; but they are significantly different from the proportions of 162 Sample A hands. 
Figure 4: (a) Proportion differences between the small stencil hands and human babies hands, (b) Variation of the proportions between the samples.

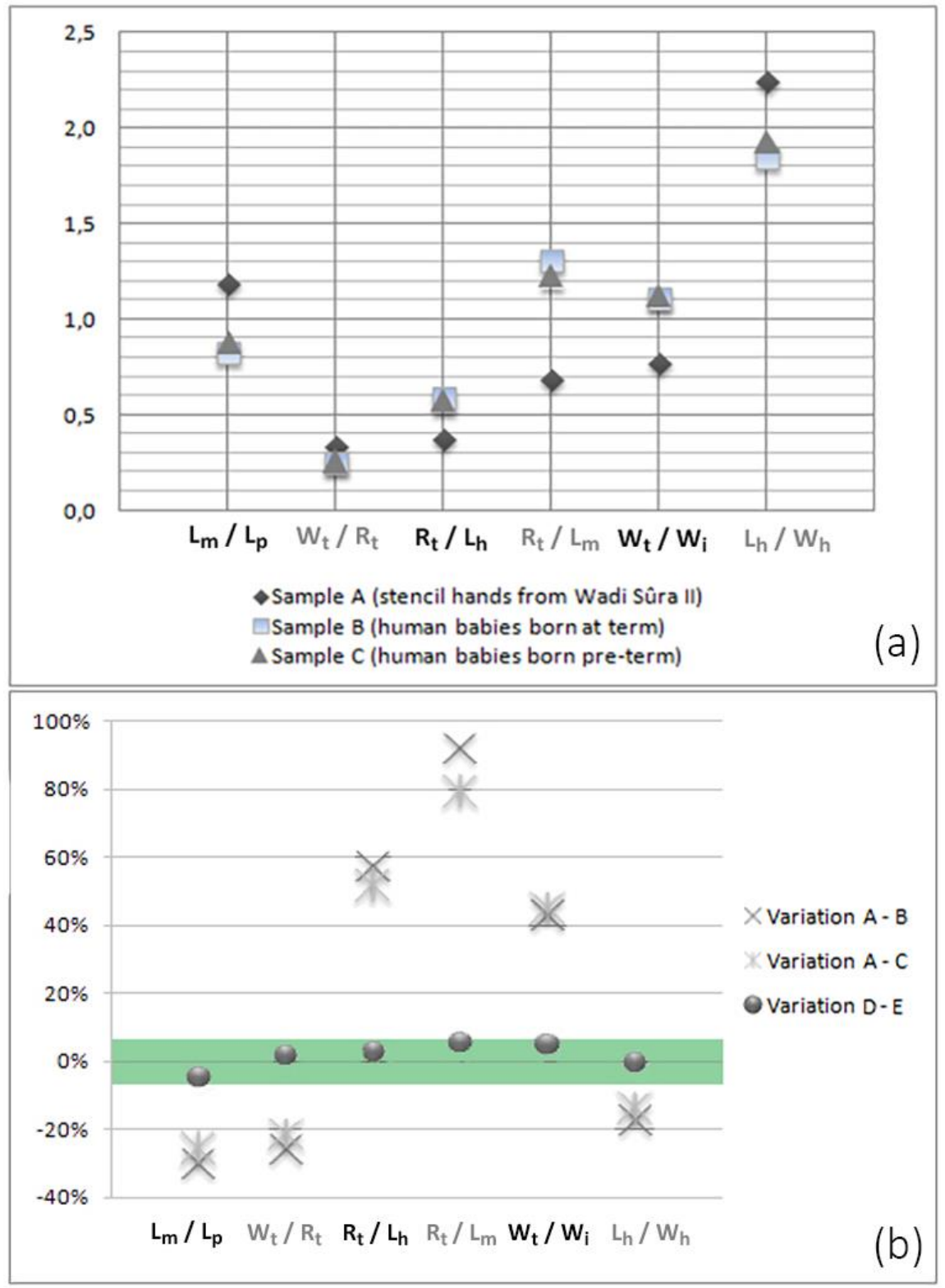

\section{Consideration of potential biases}

Potential biases could affect the data in the comparisons of measurements. The main bias would result from the fact that the data of Sample A have been taken on a painting result, whereas measures for Samples $B$ and $C$ have been taken directly on hands. Other potential biases can be stressed, such as anthropomorphological differences between the Early or MidHolocene populations and the modern populations, or differences due to the geographical origin of the samples. To what extent could these potential biases affect the results?

If we assume as an initial postulate that potential biases arise regardless of the age of the individuals, we could try to measure the degree to which they affect the results by comparing on the same parameters 30 large hand stencils from Wadi Süra II (named Sample D) with 30 hands of a current adult population (Sample E) (Tab. A2). The aim was to quantify the average impact of the biases between the two distinct populations. The results of the T-test are very heterogeneous depending on the parameters and thus inconclusive (Tab. A5). We 
calculated the variations between the Samples $D$ and $E$. If the differences between the Sample $A$ and the Samples $B$ and $C$ are due to these biases, we would expect that the variations of proportions or size would be roughly in the same range from the stencil object to its painting.

The results show that the variations between the small hands blown in the shelter and the hands of pre-term and at term babies are much higher than the variations observed between human adult hands and large hand stencils from Wadi Sūra II shelter. The biases on adult hands do not exceed a 5.5\% average deformation, from the hand to its stencil (Fig. 4b, Tab. A8). The conclusion is that potential biases cannot solely explain the differences that we have observed between the small stencil painted hands and the hands of young humans.

\section{Hand morphology and proportions study}

On the Wadi Sūra II small stencil hands, the ray of the thumb (first digit) is rather short, in comparison to the length of the medius (third digit) as well as to the length of the hand (Fig. 5, tab. A7). We also note that the anatomical position of the thumb is also quite different (Fig. 2). On the stencil hands, the base of the thumb lays in the proximal alignment of the metacarpals; whereas on human hands, the thumb is not aligned with the other fingers and appears to be more opposable. This constitutes a serious anatomical argument to exclude the possibility of human hands. A 3D graph gathering the five samples according to three featuring ratios (Fig. 5) shows that all the human hands (both modern hands and archaeological stencil hands) gather in a single cloud, while hands from Sample A are scattered outside of the group. Hand proportions clearly differ between the human samples (Samples B, C, D, E) and the other group (Sample A).

In conclusion, the small stencil hands of Wadi Sūra II have an extremely low probability of belonging to human babies or fetuses, and the differences observed cannot be explained by distortions that are due to potential biases.

Figure 5: 3D-Plot of the samples according to three ratios (XLStat 2015). Sample B, C, D and $\mathrm{E}$ gather in a cloud, showing that the morphological proportions of human hands are in the same range, whether adult or babies, hands or stencils. Sample A dots are all outside the cloud of human hands proportion.

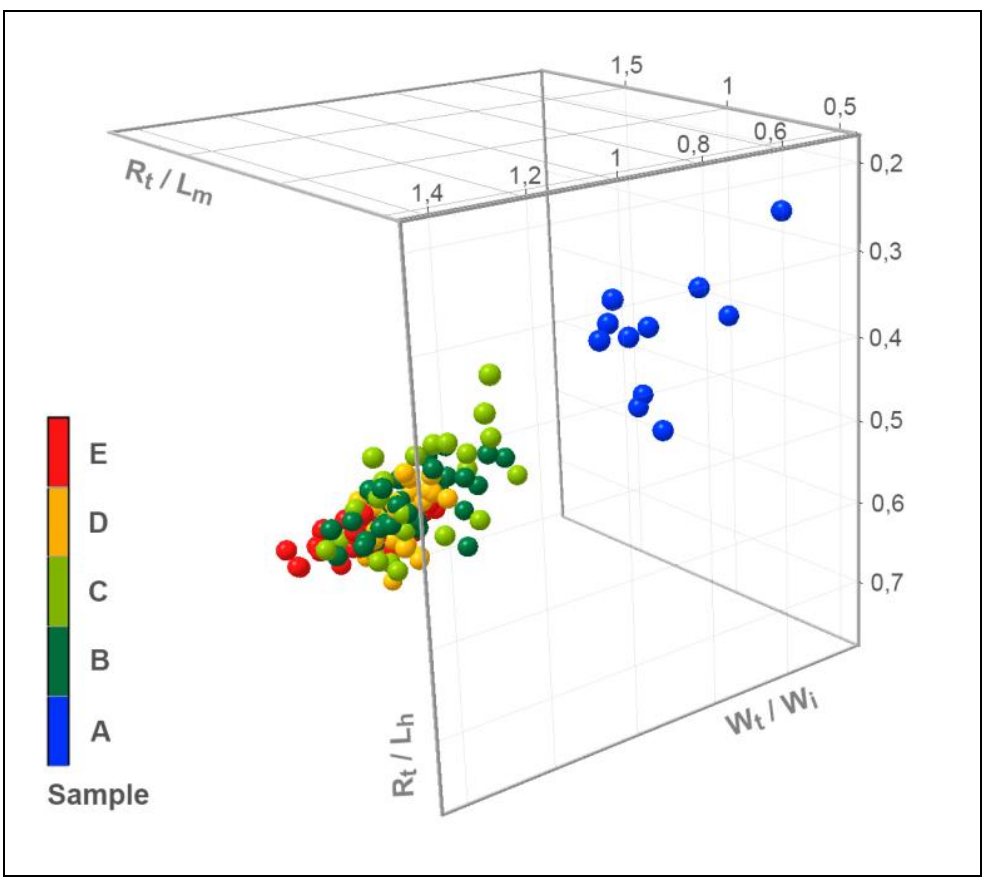


Figure 6: Hands of (a) a newborn from sample B, (b) a 4-year old Crocodylus from the zoological garden of the University of Tel Aviv, (c) an adult Varanus griseus from the wild, (d) an adult Varanus griseus from the Zoo of Moscow - palm length $25 \mathrm{~mm}$.

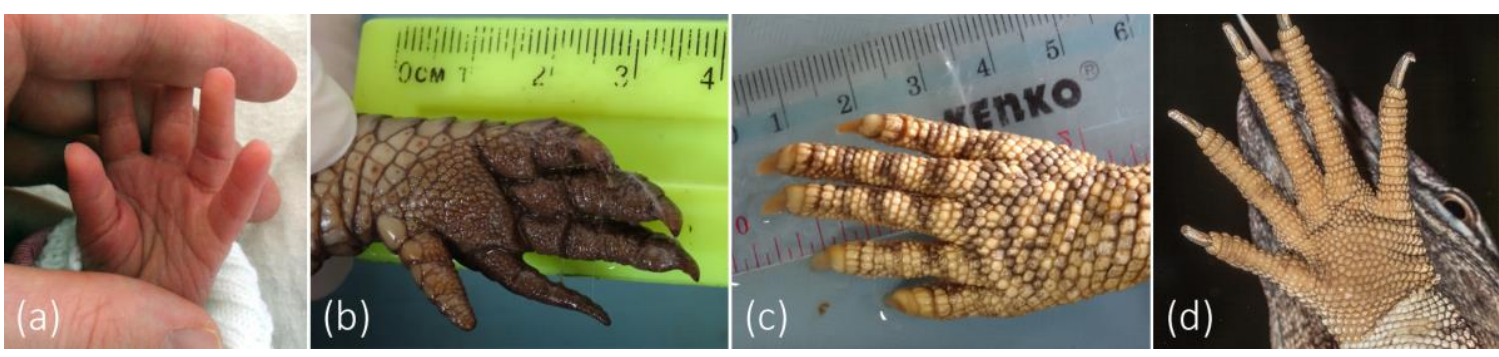

\section{Alternative hypotheses}

Alternative hypotheses are those of a modeled hand (made from wood, clay or any other material), animal hands, or modified stencils. The individual and collective postures of the fingers and phalanxes, according to criteria of functional morphology and biomechanics, are consistent with an articulated hand. The position of every finger and the distance between them also differ a little bit from one hand to another, which is particularly visible on the frieze (cf. infra \& Fig. 1). No trace of retouch is visible. It could corroborate the hypothesis of the stencil being a hand of a creature - whether dead or alive - with pentadactyl hands or feet, like non-human primates (small monkeys), other mammals, or reptiles. Young Cercopithecidae are matching in terms of hand length and elongated proportions ${ }^{19}$ but the thumb on their hands is opposed, as it is in human hands ${ }^{20}$, and the finger tips are usually not so pointed.

On purely morphometric criteria, the most compelling comparisons are found among reptiles, and especially either young crocodile (Crocodylus sp.) or varan forefeet (Varanus sp.) (Fig. 6). Varanus forefeet are much smaller than their hindfeet, whose morphological proportion are differing, so that only the forefeet of Varanus sp. could match with Wadi Sūra II stencils. In the desert or semi-desert area of the Gilf el-Kebir, Varanus griseus griseus is the most likely subspecies due to its known distribution range and its natural habitat ${ }^{21}$, but a crocodile's forefoot is not to be excluded since it could have been transported. Nile crocodile is evidenced across the Sahara during the Holocene by rock $\operatorname{art}^{22}$ and bone remains ${ }^{23}$, and was still found alive in the Tibesti ${ }^{24}$ and the Tassili in the early $\mathrm{XX}^{\text {th }}$ century ${ }^{25}$.

On each hand from Sample A, fingers show important length differences which would rather fit with the morphological specificities of crocodile or varan hands/forefeet (contrary to primate hands), having unequal numbers of phalanxes: respectively 2-3-4-4-3 and 2-3-4-5-326. Distal phalanxes terminate in a pointed horny claw whose shape conforms to the tip of Sample A digits. We compared the measurements of Sample A with a Varanus griseus griseus adult and male specimen from the Steinhardt Museum of Natural History of Tel Aviv University. Out of the seven measurements taken on its forefeet, six match the dispersion of Sample A $\left(\mathrm{W}_{\mathrm{i}}=5,4 ; \mathrm{W}_{\mathrm{t}}=4,5 ; \mathrm{L}_{\mathrm{m}}=26,5 ; \mathrm{L}_{\mathrm{p}}=19,5 ; \mathrm{L}_{\mathrm{h}}=46 ; \mathrm{W}_{\mathrm{h}}=23\right)$, and one $\left(\mathrm{R}_{\mathrm{t}}=26\right)$ is below the threshold of $5 \%$ probability. A comparative morphometric analysis with juvenile crocodiles is in progress.

\section{Discussion and conclusion}

Animal hand or foot stencils are not as common as human ones in the rock art record. Emu foot stencils are evidenced in the Carnavon Gorge and the Tent Shelter in Australia, 
choike/nandu (birds of the genus Rhea) stencils in the rock art of La Cueva de las Manos in Argentina, bird stencils in Arnhem Land in Australia ${ }^{27}$, among others. All these animal stencils are made with tridactyl feet. As such, as far as we know, the Wadi Sūra II shelter would represent the first record ever identified of non-human pentadactyl hand stencils in the world rock art.

253

254

255

256

257

258

259

260

261

262

263

As for chronology, the hand stencils of Wadi Sūra II relate to the earliest phases among rock paintings on the shelter wall ${ }^{28}$. No direct dating of the painting has been done so far, however according to the relative chronology and contextual evidence, this phase could be placed tentatively into the second half of the VIIth millennium BC and the VIth millennium BC, around $6000 \mathrm{BC}^{28}$. Representation patterns suggest that the very small hand stencils are most probably contemporaneous with the adult ones. The layout of the tiny stencils is significant. They are all located approximately at the same height, at around $1.80 \mathrm{~m}$ above ground level as it was at the time of the discovery of the shelter. Five of them are aligned in the same direction like a frieze (Fig. 1). Their total number is only 13 out of about 900 stencils, this means less than $1,5 \%$. If the same hand was used for stencilling, this could represent an isolated experience, done once, maybe using a unique animal hand.

The varan is an animal associated with a strong symbolic universe amongst Saharan and Sahelian populations, who represented it in rock art ${ }^{29,} 30$. For André Jodin, "the sacred nature of this animal for the [subactual] Libyan populations is undoubtful"31. Varans appear as protective animals to which various functions are assigned: chthonian animals related to the founding of the villages and to origins in general, protective or apotropaic body parts worn as amulet by the Tuaregs, etc. Crocodiles are also linked to old-established beliefs about creation, destruction or regeneration, mainly recorded in the Nile Valley. Both animals have not yet been identified by archaeology - whether in rock art or by bone remains - in the Gilf el-Kebir.

Whereas other shelters of the region mostly display scenes of everyday life (pastoralism, hunting), Wadi Sūra II is host to numerous paintings whose content is more obviously symbolic, such as composite beasts. The presence of animal stencils in this particular shelter suggests that they could have been done in the context of paintings expressing beliefs related to nature. The particular layout of the pair of tiny hands in the pair of human hands seem to indicate a close - if not fusional - connection between animals and human, in the generic sense of the term (Fig. 2). Our identification of the use of an animal (most probably a reptile) hand or forefoot as a stencil in the rock art of Wadi Sūra is a significant discovery that sheds a new light on the symbolic universe of the Early Holocene populations from the Eastern Sahara.

\section{References}

[1] Embabi, N. S., 2004. The Geomorphology of Egypt: Landforms and Evolution, volume I. The Nile Valley and the Western Desert. The Egyptian Geographical Society, Cairo, pp. 353362.

[2] Gasse, F., Téhet, R., Durand, A., Elisabeth, G. \& Fontes, J.-C., 1990. The arid-humid transition in the Sahara and the Sahel during the last deglaciation. Nature 346, 141-146. [3] Almasy, L. de, 1936. Récentes Explorations dans le Désert Libyque. Publications de la Société Royale de Géographie d'Egypte, Le Caire.

[4] Semplici, A., 2003. Arte rupestre: una Capella Sistina nel Sahara. Airone 267, 59-74. [5] Zboray, A., 2009. Rock Art of the Libyan Desert. DVD 2nd Expanded Edition. Fliegel Jezerniczky Expeditions Ltd., Budapest. 
[6] Jouve, A., 1996. Abri sous-roche, in: Leroi-Gourhan, A. (ed.). Dictionnaire de la Préhistoire, $2^{\mathrm{e}}$ édition augmentée et mise à jour. Presses Universitaires de France, Paris, pp. 3[7] Jouve, A., Leclerc, J. and Tarrête, J., 1996. Grotte, , in: Leroi-Gourhan, A. (ed.). Dictionnaire de la Préhistoire, $2^{\mathrm{e}}$ édition augmentée et mise à jour. Presses Universitaires de France, Paris, pp. 473-474.

[8] Honoré, E., 2014. Negative rock paintings in Wadi Sūra II shelter (Gilf el-Kebir, Egypt). 'African Archaeology without Frontiers'. Abstract of Papers: $14^{\text {th }}$ Congress of the PAA, $22^{\text {nd }}$ Biennal Meeting of the SAfA, p. 57.

[9] Kuper, R. et al., 2010. Report on the third field season of the Wadi Sura Project (Gilf Kebir, SW Egypt) in automn 2009. University of Köln, Köln, p. 13.

[10] Le Quellec, J.-L., 2014. Les racines de la mythologie égyptienne. Dossier pour la Science Hors-série 80, p. 30.

[11] Le Quellec, J.-L., de Flers, P., de Flers, P., 2005. Du Sahara au Nil. Peintures et gravures d'avant les Pharaons. Fayard, Paris, p. 251.

[12] Gunn, R., 2006. Hand sizes in rock art: interpreting the measurements of hand stencils and prints. Rock Art Research 23(1), 97-112.

[13] Snow, D., 2006. Sexual dimorphism in European Upper Paleolithic cave art. American Antiquity 78(4), 746-761.

[14] Sinclair, A., Nelson, E., Hall, J., Randolph-Quinney, P., 2013. Caught Red-Handed: The Application of Geometric Morphometric Shape Statistics in the Analysis of Palaeolithic Cave Art (poster). Unravelling Human Origins Conference, Cambridge.

[15] Honoré, E., Rakza, T., Deruelle, P., submitted. Hand morphology of human babies at birth, from 26 to 41 weeks estimated gestational age. Data in Brief.

[16] Sharpe, K. and Van Gelder, L., 2005. Techniques for Studying Finger Flutings. Bulletin of Primitive Technology 30, 68-74.

[17] Nowak, E., 2004. Functional assessment of a child's hand for the needs of ergonomics and rehabilitation. Ergonomia IJE \& HF 26(3), 232-233.

[18] Chazine, J.-M., Noury, A., 2006. Sexual Determination of Hand Stencils on the Main Panel of the Gua Masri II Cave (East-Kalimantan/Borneo-Indonesia). International Newsletter on Rock Art 4, 21-26.

[19] Etter, H.-U., 1975. Morphologisch und metrisch-vergleichende Untersuchung am Handskelet rezenter Primaten. Gegenbaurs morphologisches Jahrbuch 120(3), 299-322. [20] Jouffroy, F., Lessertisseur, J., 1960. Les spécialisations anatomiques de la main chez les singes à progression suspendue. Mammalia 24(1), 93-151.

[21] Baha el Din, S., 2006. A Guide to the Reptiles and Amphibians of Egypt. The American University in Cairo Press, Cairo - New York, pp. 189-191.

[22] Jelinek, J., 2004. Sahara : Histoire de l'art rupestre libyen. Jérôme Millon, Grenoble.

[23] de Smet, K., 1999. Status of the Nile crocodile in the Sahara desert. Hydrobiologia 391, 81-86.

[24] Brito, J. C., Martinez-Freiriz, F., Sierra, P., Sillero, N., Tarroso, P., 2011. Crocodiles in the Sahara Desert: An Update of Distribution, Habitats and Population Status for Conservation Planning in Mauritania. PLoS ONE 6(2), 1-10.

[25] Seurat, L. G., 1925. Le Crocodile de l'oued Ahrir (Tassili des Ajjers) d'après des documents communiqués par le Gouvernement Général de l'Algérie. Bulletin de la Société d'Histoire Naturelle d'Afrique du Nord 16, 150-153.

[26] Hall, B. K. (ed.), 2007. Fins into Limbs: Evolution, Development and Transformation. The University of Chicago Press, Chicago. [27] Taçon, P., Langley, M., May, S. K., Lamilami, R., Brennan, W., Guse, D., Ancient bird stencils discovered in Arnhem Land, Northern Territory, Australia. 
[28] Watrin, L., Saad, K., Honoré, E., 2008. The headless beasts of Wadi Sûra II Shelter in the Western Gilf el-Kebir: new data on Prehistoric Mythologies from the Egyptian Sahara. In:

345 Koussoulis, P. (ed.), Abstracts of papers, Xth International Congress of Egyptologists. International Association of Egyptologists \& the University of the Aegean, Rhodos. [29] Souville, G., 1991. Essai d'interprétation des gravures rupestres du Haut Atlas marocain. Comptes-rendus des séances de l'Académie des Inscriptions et Belles-Lettres 135(4), 767 782.

[30] Réganon, M., 1978. Deux gravures rupestres dans le haut-atlas. Journal des Africanistes 48(2), 97-99. [31] Jodin, A., 1964. Gravures rupestres du Yagour (Haut-Atlas) : Analyse stylistique et thématique. Bulletin d'Archéologie Marocaine 5, 47-116.

Supplementary information The appendix is composed of 8 tables of data (A1 to A8).

Acknowledgements The first author is funded by the British Academy and the Royal Society as a Newton International Fellow in the United-Kingdom and is very grateful for the strong support of these two organizations. We thank the Egyptian authorities for their support. We also thank all parents and individuals who have agreed to take part in the morphometric data collection. We are grateful to Dr S. Amblard-Pison, Dr A. Person, Dr S. Bouquillon-Delerive, Prof P. Thomas, Dr P. S. Randolph-Quinney, Prof. F. Thackeray, Prof. J. Robb, Dr J. Etling and L. Watrin for discussion and advice, to Dr S. Meiri and E. Maza from the Department of Zoology of Tel Aviv University, and S. Kudryavtsev from the Moscow Zoo for the pictures of Varanus griseus and Crocodylus niloticus specimens, to M.-C. Broudic for advices concerning the statistical analysis, to C. Duriez for the IT support and to Prof J. Robb for the review. The anonymous reviewers are warmly thanked for their careful review and relevant suggestions. 